\title{
Uma Abordagem Fuzzy na Determinação de Riscos em Seguro de Vida
}

\author{
Lucas Pereira Lopes ${ }^{1}$ \\ Instituto de Ciências Sociais Aplicadas, UNIFAL-MG, Varginha, MG. \\ Taiane Meira Silva ${ }^{2}$ \\ Instituto de Ciências Sociais Aplicadas, UNIFAL-MG, Varginha, MG.
}

\begin{abstract}
Resumo. O matemático Zadeh [1] introduziu a teoria fuzzy que nos permite a manipulação de dados imprecisos e incertos. A lógica fuzzy, também conhecida como lógica nebulosa ou lógica difusa, é uma ferramenta essencial na tomada de decisão, tendo como finalidade, transformar expressões imprecisas em valores numéricos. Considerando uma extensão da lógica clássica, na quais valores intermediários entre verdadeiro e falso são representados, a lógica fuzzy propõe um tratamento matemático a certos termos linguísticos subjetivos, como aproximadamente, em torno de médio, alto, dentre outros.

A lógica fuzzy se fundamenta na existência de conjuntos denominados de conjuntos fuzzy, que podem ser representados por funções de pertinência. Lógica fuzzy se destacou devido a sua grande capacidade no tratamento de sistemas especialistas que incorporam imprecisão em algumas de suas variáveis de estudo, surgindo os sistemas de regras fuzzy. A teoria dos conjuntos fuzzy tem sido utilizada em várias áreas, como em análise de dados, sistemas especialistas, controle e otimização, biomedicina, biomatemática e estatística. Como por exemplo, na área de administração, a lógica fuzzy pode ser utilizada para auxiliar um especialista a tomar uma decisão quanto ao porte de uma empresa, e em ciências atuariais, auxiliar uma seguradora na subscrição de um determinado seguro.

Um dos ramos da Ciência Atuarial é o estudo de seguro. De acordo com a Agência Nacional de Saúde Suplementar (ANS), a penetração dos Planos de Saúde no Brasil cresceu aproximadamente 50\% desde o ano de 2001, alcançando mais de 50,6 milhões de indivíduos em setembro de 2014. No entanto, em 30 de Setembro de 2014, apenas $24,7 \%$ da população brasileira possuíam Planos de Saúde. Com o crescimento econômico do País, o mercado de seguros acompanhou o mesmo, fazendo com que as seguradoras sejam responsáveis por uma grande parcela da população do Brasil. Com um número cada vez maior de segurados, um problema enfrentado hoje pelas seguradoras na área de saúde é a capacidade de transformar a avaliação da saúde dos
\end{abstract}

\footnotetext{
${ }^{1}$ luccas.lopes@live.com

2 taianemeira@outlook.com
} 
beneficiários de uma forma rápida e prática em um índice de risco para a seguradora. Logo, as seguradoras tem uma carência em sistemas que consigam adaptar as avaliações médicas a riscos em suas estruturas e fórmulas de precificação de seguros.

Neste trabalho é proposto um sistema baseado em regras fuzzy [2] para identificar quando um paciente tem um risco mais elevado para a seguradora do que outro paciente, dessa maneira, a mesma pode se prevenir e melhorar a sua forma de precificação de seguros. Utilizamos no trabalho a pressão arterial e o nível de colesterol como variáveis de entrada, logo sendo o risco coronariano a saída. Um sistema baseado em regras fuzzy é baseado em regras, tais como foram usadas: "Se a pressão arterial está alta e o nível de colesterol é médio, então o risco é alto". Para fazer a inferência utilizou o método de Mandani, e a desfuzzyficação o método de centro de área.

O papel do especialista em seguro saúde foi de suma importância para a formulação das regras. É importante ressaltar que neste modelo não foi considerado outros riscos associados à saúde, e sim os dois principais para o risco coronário. Sendo assim, o valor do risco coronário estimado pelo modelo serviria apenas para nortear algumas intervenções da seguradora, ajudando-o a tomar decisões a partir da identificação da posição do segurado em seu estado de saúde.

Sendo assim, consideramos que o método proposto, baseando em uma descrição qualitativa dos conhecimentos disponíveis, demonstrou possuir boa capacidade preditiva para o risco coronário dos segurados.

Palavras-chave. Fuzzy, Seguro Saúde, Sistema Fuzzy, Base de regras.

\section{Agradecimentos}

Aos professores do Instituto de Ciências Sociais Aplicadas da Universidade Federal de Alfenas-MG e à equipe da SBMAC pela oportunidade.

\section{Referências}

[1] L. A. Zadeh, Fuzzy Sets, Information and control, v. 8, p. 29-44, (1965).

[2] M. S. Peixoto, Sistemas Dinâmicos e Controladores Fuzzy: um Estudo da Dispersão da Morte Súbita dos Citros em São Paulo, Tese de Doutorado, IMECCUnicamp, (2005). 